\title{
Zamba y la revolución industrial. Propaganda kirchnerista para explicar la economía a los niños argentinos*
}

\author{
Pedro Vázquez-Miraz** \\ Recibido: 2020-02-16 • Enviado a pares: 2020-03-10 \\ Aprobado por pares: 2020-04-21 - Aceptado: 2020-05-22 \\ https://doi.org/10.22395/angr.v19n37a7
}

\begin{abstract}
Resumen
El presente trabajo de investigación analiza un capítulo de televisión infantil titulado "La asombrosa excursión de Zamba a la Revolución Industrial", programa emitido en el año 2014 en Argentina. Este es una pieza audiovisual del célebre dibujo animado argentino La asombrosa excursión de Zamba. Este programa televisivo público fue creado en el año 2010 por la productora El Perro en la Luna, en pleno período peronista-kirchnerista, y se mantuvo activo con bastante popularidad hasta los primeros años del Gobierno conservador de Mauricio Macri. Por medio de un análisis cualitativo de este material se identifica la manera en que este producto presenta a los niños argentinos las diferencias entre el sistema económico capitalista y socialista mediante las creaciones animadas de Adam Smith y Karl Marx. Este programa se basa en la valencia de los discursos realizados por estos dos personajes históricos, las consecuencias de sus actos y los contextos y ambientes en los que son representados por parte del producto. En este sentido, el programa representa un relato histórico e ideológicamente tratado que identifica la trama animada con el proyecto político del Gobierno peronista que dirigió a Argentina en la época 2003-2015. Como conclusión principal, se pudo determinar que el formato del programa denota un profundo sesgo propagandista que incide en la apropiación de una versión histórica y del modelo económico, pues parte de un medio público hacia un público infantil.
\end{abstract}

Palabras clave: televisión; dibujos; educación masiva; propaganda; kirchnerismo; Argentina.

Artículo inédito soportado por el proyecto Estudios de género: economía, comunicación y educación (2018) realizado bajo el amparo del grupo de investigación Desarrollo, Salud y Desempeño Humano de la Universidad Tecnológica de Bolívar, Colombia.

" Doctor en Ciencias Sociales y del Comportamiento, Universidad de La Coruña, La Coruña, España. Profesor, Universidad Tecnológica de Bolívar, , Cartagena, Colombia. Correo electrónico: pvasquez@utb.edu.co. Orcid: http://orcid.org/0000-0002-5801-1728 


\title{
Zamba and the Industrial Revolution. Kirchnerist Propaganda for Explaining Economy to Argentinian Kids
}

\begin{abstract}
This research work analyzes a chapter of children television titled "La asombrosa excursión de Zamba a la Revolución Industrial" (Zamba's fantastic trip to the industrial revolution), program broadcasted in 2014 in Argentina. Is an audiovisual production based on the renowned comic series La asombrosa excursión de Zamba (Zamba's fantastic trip). This public television program was created in 2010 by the producer house El perro y la luna (The moon and the dog), in the plenary Peronist-kirchnerist period and was popular until the first year in office of the conservative president Mauricio Macri. Through a quantitative analysis of this material, the study identifies how this product presents to Argentinian kids the differences between the socialist and the capitalist economic systems through animated creations of Adam Smith and Karl Marx. This program is based upon the valency of the speeches performed by these historical characters, the consequences of their actions and the contexts and environments in which they are represented by the audiovisual product. Thus, this program represents a historical and ideologically managed narrative that identifies the animated thread with the political project of the Peronist government that ruled Argentina in the years 2003 to 2015. As a min conclusion, the study could determine that the format of the program denotes an evident propaganda bias that influences in the appropriation of a historical version and an economic model, given that it takes place in a public media and is directed towards children audience.
\end{abstract}

Keywords: television; comics; massive education; propaganda; Kirchnerism; Argentina.

\section{Zamba e a Revolução Industrial. Propaganda kirchnerista para explicar a economia para as crianças argentinas}

\begin{abstract}
Resumo
Este trabalho de pesquisa analisa um episódio de um programa de televisão infantil intitulado "A assombrosa excursão de Zamba à Revolução Industrial", emitido em 2014 na Argentina. Esse é um trabalho audiovisual do conhecido desenho animado argentino La asombrosa excursión de Zamba. Esse programa de televisão pública foi criado em 2010 pela produtora El perro en la luna, em pleno período peronista-kirchnerista, e se manteve ativo com bastante popularidade até os primeiros anos do governo conservador de Mauricio Macri. Por meio de uma análise qualitativa desse material, é identificada a maneira em que esse produto apresenta às crianças argentinas as diferenças entre o sistema econômico capitalista e socialista mediante as criações animadas de Adam Smith e Karl Marx. O programa está baseado na vigência dos discursos realizados por essas duas personagens históricas, nas consequências de seus atos e nos contextos e nos ambientes em que são representadas por parte do produto. Nesse sentido, o programa representa um relato histórico e ideologicamente tratado que identifica o enredo animado com o projeto político do governo peronista que dirigiu a Argentina entre 2003 e 2015. Como conclusão principal, pôde-se determinar que o formato do programa denota uma profunda tendência propagandista que incide na apropriação de uma versão histórica e do modelo econômico, pois parte de um meio público para um público infantil.
\end{abstract}

Palavras-chave: televisão; desenho animado; educação massiva; propaganda; kirchnerismo; Argentina. 


\section{Introducción}

Los dibujos animados son representaciones de la vida social; funcionan como modelos arquetípicos que condensan modos de hacer y de ser, y corresponden a patrones éticos e ideológicos con funciones y esquemas efectivos. En ese contexto, los dibujos y series animadas pueden ser usados como herramientas de representación y reproducción social y como esquemas de socialización y aprendizaje. Pero también pueden ser usados como propaganda, entendida como "el intento deliberado de persuadir personas para pensar y comportarse de la manera deseada" (Taylor, 2003, p. 6). Esta estrategia ha sido implementada en diferentes contextos y medios con distintos propósitos (Ahmad et al., 2019). Además ha estado presente como referente legitimador del sistema económico imperante de muchos estados, y como oposición a otros sistemas posibles. Tuvo una evidente notoriedad y relevancia durante la época de la Guerra Fría, ya fuera del lado de los países capitalistas (Honsa, 2012; Jack, 2015) o de las naciones socialistas (Fedorov, 2015, 2016; Riabov, 2018). En consecuencia, la propaganda ha sido dirigida como un dispositivo de adiestramiento y como mediador de voluntades. Por tanto, esta influye en la postura que tienen los ciudadanos a la hora de tomar decisiones y definir roles en una sociedad.

Estas prácticas se acentúan con los conflictos entre actores políticos y los procesos de cambio y ruptura. Como indica Gambina (2016), la crisis económica mundial y los continuos cambios políticos ocurridos a principios del siglo XXI en América Latina, han impuesto un debate sobre cómo se debe estudiar y explicar las relaciones económicas e históricas al grueso de la sociedad. Los proyectos políticos con perspectiva de poder producen explicaciones verosímiles de tales fenómenos a grandes públicos, para lo cual echan mano de las prácticas de propaganda y de significación. Estas producen interpretaciones más o menos consistentes de la economía y la historia que justifican las acciones impulsadas por cada proyecto político en el radio de acción donde opera dicha propaganda. La discusión teórica en economía y política no escapa a una confrontación teórica entre la confrontación de las teorías keynesianas y neoliberales y el paradigma marxista actualizado (Gambina, 2016).

De igual modo, la operación ideológica se extiende hasta la forma de valorar y concebir la historia oficial de las naciones, así como sus procesos de construcción de identidad y autoafirmación en la revaloración de los mitos y narraciones que soportan el nacimiento de los Estados nacionales modernos. En la década pasada, los gobiernos de las repúblicas de Latinoamérica generaron intensos procesos de autoafirmación de sus procesos históricos a propósito de la celebración del Bicentenario de la Independencia. Estas conmemoraciones, que tienen un carácter de refundación de los proyectos nacionales y de sus referentes históricos, también se apoyaron en la producción de propaganda. Hicieron mensajes funcionales y convenientes, así 
como conceptos emotivos como la patria, la unidad nacional, la depuración de las amenazas internas y externas de la nación y la idoneidad y aceptación de los actuales valores y actores políticos que concentran y representan el poder.

Una arena determinante en la consolidación de versiones y actores en el poder es el campo de la educación y de los procesos de formación en general, sean o no institucionales. Estos se convierten en una plataforma donde el Estado y su estructura de control expanden contenidos e ideologías que imprimen un estilo y un carácter presente en los referentes instructivos y en el tipo de formación ofrecida por el sistema educativo. La instrucción se soporta en el desarrollo de planes y modelos escolares que socializan e insertan preceptos y modos de aprendizaje que van en sintonía con la perspectiva ideológica a la que se adhiere el proyecto de nación. Con estos modelos el Estado valida, distribuye y consolida tipos de aprendizaje, idearios políticos y concepciones de mundo sobre los territorios y las poblaciones donde tiene jurisdicción.

En la Argentina de comienzos de este siglo, el proyecto político impulsado por el kirchnerismo se afianzó al implementar un nuevo ordenamiento. La agenda política de la familia Kirchner se soportó en idearios del peronismo, así como en contenidos programáticos cercanos al pensamiento de izquierda y vinculados a lo que se conoce en América Latina como el "socialismo del siglo XXI". Producto de esta afirmación ideológica, se desarrollaron distintas estrategias de difusión en donde los medios de comunicación del Estado y su función de narradores históricos jugaron un papel fundamental. Definir conceptualmente los partidos políticos argentinos y en particular el movimiento kirchnerista no es tarea sencilla, pues la tradicional dicotomía izquierdaderecha resulta insuficiente para poder explicar las particularidades de la política de esta nación sudamericana. En palabras de Retamozo y Schuttenberg (2016) "la irrupción del peronismo y los intentos de conceptualizarlo evocaron la necesidad de otros clivajes: civilización o barbarie, autoritarismo o democracia, nacional o colonial" (p. 116). Por tanto, se ubica esta corriente política dentro de los ejes izquierda-derecha y peronismo-gorilismo (Retamozo y Schuttenberg, 2016), por lo que el kirchnerismo es un flexible peronismo de izquierdas. En este contexto tomó forma la animación La asombrosa excursión de Zamba, contenido en el que se centra nuestro manuscrito1.

En América Latina, uno de los periodos de mayor transformación de la narrativa histórica fue la celebración del segundo centenario de la Independencia. Este estuvo marcado por campañas mediáticas que generaron los gobiernos de la región

Este programa fue un producto de animación realizado por la productora El Perro en la Luna (Álvarez-Gandolfi, 2013), cuyo objetivo inicial era presentar a los niños del país austral, de una manera amena y divertida, los hechos históricos que acontecieron durante el proceso de independencia del antiguo Virreinato del Río de La Plata e introducir los conocimientos históricos fundamentales del nacimiento y formación de la nación argentina. La emisión de este programa infantil empezó en julio del 2010, con motivo de la celebración de la efeméride del bicentenario de la Revolución de Mayo (Murolo, 2013; Crivelli, 2015). 
para exaltar las características de cada país, su historia como nación y el heroísmo o dignidad de sus fundadores u otros actores históricos destacados por las pretensiones políticas de los gobiernos en ejercicio. No fue óbice que los gobiernos de uno u otro país fueran de orientaciones ideológicas divergentes. Todos los mandatarios apostaron por celebrar el bicentenario como un momento de plenitud y madurez de un Estado progresista y de vanguardia, adaptado a los desafíos del mundo actual. El bicentenario sirvió, entonces, como una plataforma de refundación en la que los actores de la política contemporánea echaron mano de modelos históricos para actualizar sus pretensiones y necesidades coyunturales. Argentina no fue ajena a este fenómeno. Para Bohoslavsky (2016), la celebración del Bicentenario fue, probablemente, la más relevante de las políticas culturales de los gobiernos kirchneristas².

El protagonista del programa fue creado por Sebastián Mignogna y Gabriel Meglio (Crivelli, 2015); y tiene por objetivo fundamental, más que enseñar la historia en sí, hacer que el público infantil se introduzca en este campo de conocimiento y comprenda el contenido histórico-pedagógico que el dibujo le ofrece (Gastaldi, 2015). Los medios elegidos para la emisión de esta propuesta fueron, primero, el canal público Encuentro ${ }^{3}$ y luego el canal infantil Pakapaka ${ }^{4}$ (Pauloni et al., 2015, p. 149; González et al., 2016), que significa en quechua "juego de niños" (Sánchez y Méndiz, 2013; Crivelli, 2015; Pauloni et al., 2015, p. 149). Este interés por crear un canal de televisión con temática infantil, ajeno a empresas transnacionales, fue defendido por ciertos sectores de la sociedad argentina como una lucha democratizadora de la comunicación audiovisual (Crivelli, 2015).

Dicho proceso se constató en el hecho de que programas como La asombrosa excursión de Zamba hubieran tenido alta repercusión desde sus primeros años de emisión (Linare y Cuesta, 2015). El éxito de este producto audiovisual, patrocinado por el Ministerio de Educación de Argentina, llevó al Gobierno argentino, presidido por Cristina Fernández de Kirchner (2007-2015), a continuar usando la animación infantil

2 Antiguos próceres y figuras históricas que defendían el ideario liberal conservador (Palermo, 2015, p. 189), tales como los presidentes argentinos Domingo Faustino Sarmiento (Rovner y Monjeau, 2017) o Bartolomé Mitre, fueron resignificados de acuerdo con las proposiciones del discurso oficial. Con esto el bicentenario cumplió con la función de redirigir la mirada y valorar, en la perspectiva del presente político, la función y la pertinencia del sentido histórico en el que se funda la idea de nación.

3 Fue pensado inicialmente como un medio público que fomentaba la conciencia política y el pensamiento crítico (Pauloni et al., 2015), y Pakapaka fue inicialmente su franja infantil (Salviolo, 2012, p. 120).

4 La parrilla televisiva de este canal ha estado compuesta por series de animación, ficción y documentales. La programación del canal se dividió en dos segmentos de edad, en sintonía con el sistema escolar argentino y el paso a la escuela secundaria. El primero, Ronda Pakapaka, estaba orientado a una audiencia infantil de dos a cinco años, mientras que Pakapaka está destinado a niños a partir de seis años (Sánchez y Méndiz, 2013). Este canal tenía la misión de presentar a la sociedad un contenido audiovisual infantil de origen autóctono, en contraposición a las producciones audiovisuales extranjeras destinadas a los niños y mayoritariamente desarrolladas por grandes corporaciones (Bernardo, 2015). 
para explicar a los menores de edad los hechos relevantes de la historia argentina y sus posibles interpretaciones en el tiempo contemporáneo. En este proceso de enseñanza destaca, sin matiz aparente, el prisma ideológico del peronismo kirchnerista (Struminger, 2012).

La polarización social que caracterizó el período de Gobierno kirchnerista, en el que se enfrentó de forma continua el oficialismo con empresas de medios de comunicación como el grupo Clarín (Sosa, 2016), fue conocido como "la grieta" —-término propuesto en el año 2013 por el periodista Jorge Lanata (Korstanje, 2016)—. Este concepto da cuenta de una continua movilización de versiones y de información enfocada que trató de legitimar el rol y la postura tanto de la oposición como del oficialismo en ese periodo. Cada uno de los bandos produjo una versión de los hechos donde la lectura de los eventos pasados era afirmada en el contexto de una coyuntura. Tanto la serie de Zamba como las líneas editoriales de la prensa porteña señalaban que el discurso y la transmisión de contenidos era una arena de lucha y reafirmación política. En este sentido, la animación no se aproximó al pasado de forma neutral (BelincheMontequín, 2019). Por consiguiente, el objetivo fundamental de este documento es analizar si el único capítulo de esta serie animada, dedicado íntegramente al ámbito económico (por ende la primera aproximación de esta audiencia a este específico campo de conocimiento), presentó esta información didáctica de manera sesgada ideológicamente o no.

\section{Metodología}

Se realizó un análisis de contenido, el cual se define como "un conjunto de técnicas de análisis de las comunicaciones utilizando procedimientos sistemáticos y objetivos de descripción del contenido de los mensajes" (Bardin, 1996, p. 29). En este contexto, se analizaron los elementos connotativos de la animación y los elementos denotativos de los principales discursos (Martín-Serrano, 1978) que se emitieron en el capítulo "La asombrosa excursión de Zamba a la Revolución Industrial"5 (Di Tirro, Fanego y Mignogna, 2014) de la serie infantil La asombrosa excursión de Zamba. Su duración temporal fue de casi veinte minutos. Se ha estudiado la valencia ${ }^{6}$ positiva y negativa

\footnotetext{
Zamba, un niño argentino que podía viajar al pasado y ver in situ los acontecimientos históricos más importantes, conoció en este capítulo a Adam Smith y a Karl Marx, quienes le hablaron de las virtudes y problemáticas de la Revolución Industrial. Adicional a lo anterior, a nivel exclusivamente pedagógico, sería interesante resaltar la fisionomía, la motivación y la actuación del protagonista de la serie animada, pues esto nos permitiría plantear una reflexión sobre cómo se adecuaron los contenidos de un programa de televisión para infantes argentinos. Zamba era un niño mestizo oriundo de la ciudad de Clorinda (ubicada en la provincia de Formosa y cercana a la frontera con Paraguay). Debido a que siempre llegaba tarde y perdía el autobús escolar, se encontraba azarosamente con diferentes artefactos que manipulaba a su antojo, a pesar de las claras instrucciones que indicaban la prohibición de hacerlo. Así fue como pudo viajar al pasado para ser partícipe de la historia argentina.

- Basándonos en la nítida diferenciación de las emociones humanas en una línea gradual que tiene dos polos extremos: placer-displacer (Levav, 2005).
} 
de los mensajes pronunciados por los personajes históricos de esta animación (con base en la carga emocional de los adjetivos calificativos empleados por ellos) y el tiempo que se le ha dedicado a estas mismas figuras (a mayor tiempo en pantalla, se consideró el personaje como más relevante). Se hizo un estudio analítico de los eventos con los que se encuentra el protagonista en su recorrido desde dos perspectivas político-económicas bien diferenciadas: capitalismo y marxismo. Estas perspectivas fueron encarnadas por Adam Smith y Karl Marx, quienes explicaron a Zamba —y a la audiencia - datos de una situación histórica concreta del pasado: la Revolución Industrial. A través de este estudio se ha pretendido identificar si este material educativo $^{7}$ fue una implementación que contuvo una eficacia ideológica, representada en procesos de socialización y consolidación de una visión específica del mundo, que se asocie a preceptos políticos y sostenga relaciones de poder.

El estudio de la carga psicoemocional que ha caracterizado a los dos personajes históricos fue analizado por medio de la revisión de las características otorgadas por la misma serie a Adam Smith y a Karl Marx. De todas ellas se destacan el acento (más positivo el neutro porque denota cercanía y más negativo el foráneo), la personalidad (más negativa la motivación por el logro y más positiva la conducta altruista) y las consecuencias de sus actos —intencionados o no- para el protagonista, las cuales pueden ser favorables o desfavorables para él.

La selección del capítulo con el que se trabajó no fue algo baladí. En este sentido, se eligió este capítulo porque su temática es puramente económica y presenta de manera dicotómica dos modelos socioeconómicos contrapuestos. Además, esta animación fue la primera aproximación teórica de muchos niños argentinos a la economía. Se pretende, entonces, si estos aspectos se pueden relacionar con la existencia de un mensaje político claro. Esta es una razón de peso porque el proyecto kirchnerista se basaba en una crítica constante a las recetas neoliberales y una defensa férrea de las mejoras sociales (Gastón-Wainer, 2018).

\section{Resultados}

En el capítulo analizado, el televidente se encontró con dos posiciones filosóficas y económicas diferenciadas claramente: una versión optimista relacionada con el capitalismo y una más crítica asociada al marxismo, es decir, se concibieron estas dos como totalmente antagónicas. Ahora bien, la línea temática argumental hizo que ambas versiones no se conciliaran. Por el contrario, los contenidos, la ambientación de

7 En la situación expuesta, es difícil de demarcar el límite entre material educativo y propaganda. La principal disparidad entre ambos conceptos radica en que el primero tiene como propósito impartir información e ideas con fines didácticos, además de que permite que el destinatario elabore una opinión propia. Por otro lado, la meta de la propaganda es dominar los pensamientos y conductas de la audiencia a través de la exposición de posiciones correctas y erróneas (Jack, 2015). 
la animación, las formas, los rostros o la situación de los personajes dieron cuenta de cómo una de las versiones fue reconocida como la adecuada en detrimento de la otra. En este sentido, la Revolución Industrial se resaltó como un proceso que afectó a las poblaciones trabajadoras, especialmente a los niños, por lo que debía ser cuestionada. Estas versiones persuadieron a Zamba de lo que era ideológicamente correcto y, de paso, dirigieron una interpretación a la audiencia infantil argentina. Fueron múltiples las diferencias observadas en el material desarrollado para un público infantil y ocurrieron sutiles desemejanzas en las interacciones de los dos economistas con el protagonista de la serie ${ }^{8}$. En este mismo capítulo, Adam Smith casi atropella accidentalmente con una locomotora ${ }^{9}$ a Zamba (figura 1) mientras que Karl Marx lo rescató de las garras de una fábrica monstruosa.

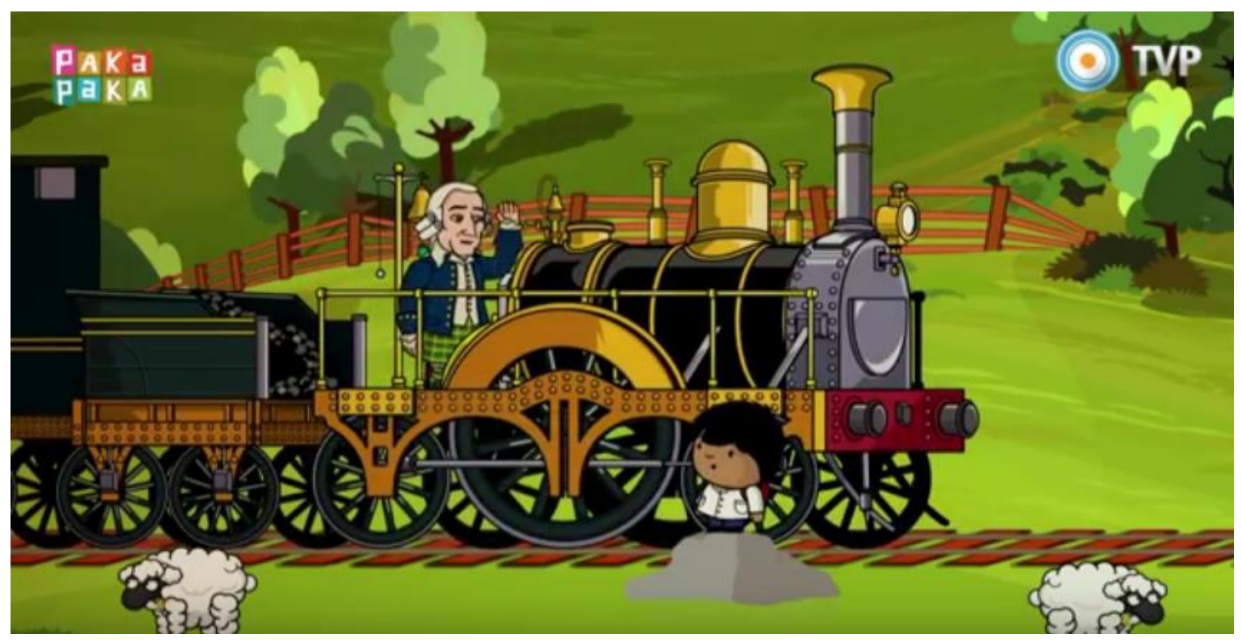

Figura 1. Saludo inicial de Adam Smith Fuente: Di Tirro et al. (2014).

Los tiempos e importancia que el capítulo le dedicó a los dos economistas y a los aspectos positivos y negativos de la industrialización no fueron un dato baladí. Si bien el economista escocés inició el capítulo y lo finalizó, ya que este presentó a los niños un breve resumen de lo aprendido después del visionado de los dibujos y su tiempo en pantalla (5:30 minutos) fue ligeramente mayor que el tiempo que el programa le dedicó a Karl Marx (4:26 minutos), los argumentos de Marx prevalecieron moralmente en el tipo de diálogos e información consignada. Estas diferencias se agudizaron en otras secciones de la animación que exhibieron la tradicional lucha de clase entre obreros y empresarios como un conflicto maniqueo entre buenos y malos (2:32 minutos). La

8 El programa usó expresiones exclamativas (detrás de un fondo de color rojo) para presentar a Karl Marx, pero esto no sucedió con Adam Smith.

9 Representación tradicional del avance tecnológico y del crecimiento productivo (Gómez, 1989). 
serie animada le dio más tiempo a los inicios del movimiento sindical, la lucha obrera y los aspectos negativos de la Revolución Industrial que a las mejoras sanitarias y otras bondades de la efectividad de los nuevos sistemas productivos. En el alegato de la visión capitalista de la economía y en el resumen final, los asuntos perniciosos de la prosperidad empresarial fueron los contenidos centrales del capítulo. Además, se trabajó con los estereotipos animados de los roles del empresario y del obrero.

En el ambiente en el que se situaron los dos personajes centrales del capítulo, hubo otras distinciones sensibles. Adam Smith, como representante de la economía capitalista, apareció de forma diacrónica en la Inglaterra del siglo XIX, en una campiña inglesa montado en una locomotora (figura 1). Finalizó su primera intervención al llegar a Londres, a la que la serie describió como una urbe triste, contaminada y rodeada de referentes negativos por ser el epicentro de la industrialización. Según el dibujo, los cambios tecnológicos produjeron efectos nocivos, como la insalubridad, que se asociaron a la industrialización, la contaminación ambiental y a las pésimas condiciones laborales para los trabajadores en las nuevas compañías. Así, el ámbito urbano fue rechazado en la animación como la antítesis de una bucólica e idílica imagen del mundo rural. En la expedición de Zamba, se señaló también la manera en que este cambio llevó a los campesinos a migrar a las ciudades para insertarse en las labores de industria bajo condiciones deplorables ${ }^{10}$. Este hecho no fue menor en el desarrollo de la trama, pues niños argentinos apreciaron que los niños que participaron de la Revolución Industrial eran maltratados ${ }^{11}$.

En el afán del capítulo por mostrar el protagonismo de Marx y Smith, se difuminaron los demás actores presentes en la Revolución Industrial. El programa describió al campesinado como un elemento pasivo, sin poder de decisión, que fue sustituido por máquinas ${ }^{12}$. De esta manera, se obviaron otras razones — además de la industrialización- por las cuales se produjo el éxodo rural. La expedición de Zamba, en lugar de poner en sintonía al público infantil sobre quiénes eran los campesinos y trabajadores de la Revolución Industrial en tantos sujetos históricos, los caricaturizó con expresiones famélicas, cuerpos desahuciados y rostros llenos de fatiga, como

10 De esta manera, se dio el mensaje directo de que el aumento de la productividad, a costa de precarizar las condiciones laborales de los nuevos obreros, fue más visible en la discriminación laboral femenina y en el trabajo infantil (Escudero, 2002).

"Aunque el trabajo infantil existía en el ámbito rural (situación que no se vió reflejada en el dibujo animado), la industrialización de las tareas agrícolas ha permitido, paradójicamente, que los menores de edad abandonaran este tipo de actividades en épocas más recientes (Rausky, 2009). En consecuencia, se pasó de una agricultura orientada al consumo doméstico a otra dirigida al mercado.

12 Al desaparecer literalmente varios campesinos por una máquina sin ningún operario, la animación plasmó la clásica interpretación ludita de la Revolución Industrial (Bartra, 2014). Esta problemática tiene total actualidad y vigencia para los postulados marxistas (Aschieri, 2017) en una época en la que muchos puestos de trabajo han sido eliminados por la imperante revolución tecnológica (Mercader-Uguina, 2017). 
unos sujetos sin identidad propia ni contexto. Esto último sazonó la carga ideológica que hizo énfasis en las consecuencias nocivas de la industrialización y expansión del modelo capitalista. Este entorno frío y despiadado resaltó más la crítica al modelo industrial, a la vez que exaltó el discurso de Karl Marx (figuras 2 y 3), exhibido como un defensor de los débiles que alegaba a favor de unas condiciones laborales dignas para los trabajadores. Así, Marx fue presentado en contraposición a los ideales de Smith — antagonista del capítulo—, quien fue exaltado en el prototipo del empresario avaro que era dueño de los medios de producción y se lucraba del sacrificio inhumano de sus empleados.

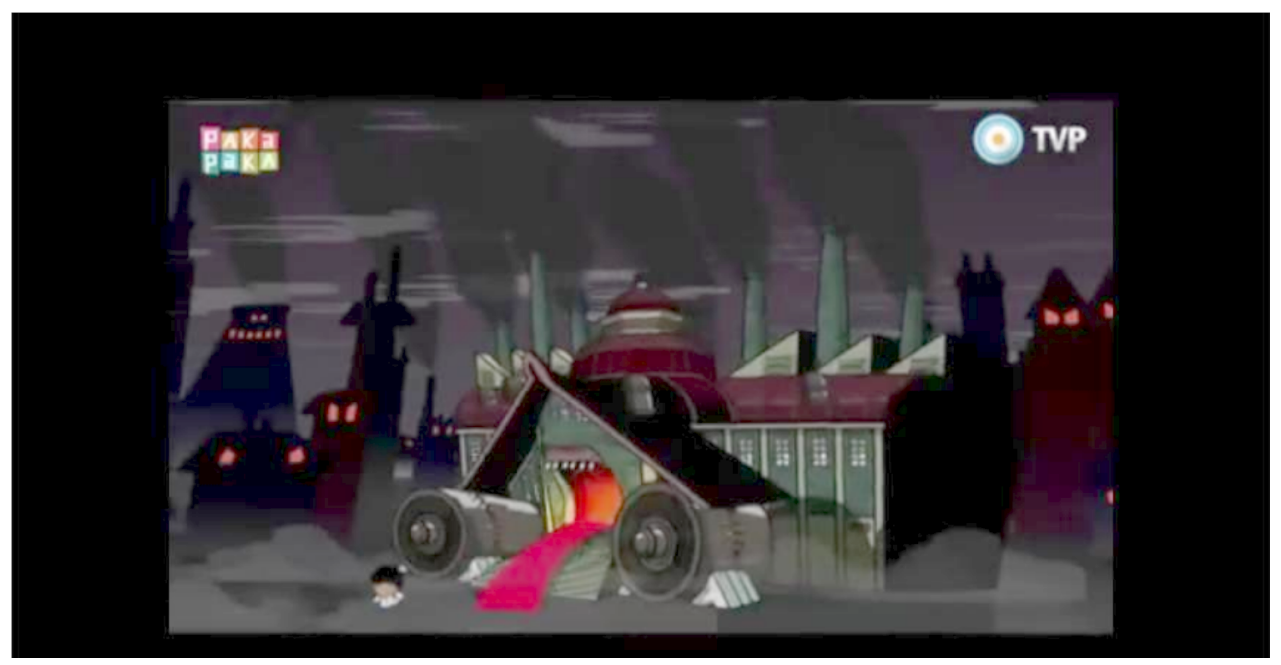

Figura 2. Representación de la industria en Zamba Fuente: Di Tirro et al. (2014).

La animación presentó a Adam Smith con los clásicos atributos estereotipados de los habitantes de Escocia, y no como el clásico "villano del capítulo"13. En la trama, la diferencia de los roles que desempeñaron ambos economistas fue notable. El economista británico introdujo a la audiencia los aspectos positivos de la industrialización, mientras que se limitó a introducir los aspectos negativos de este proceso de una manera lacónica y pasiva. Esta conducta se contrapuso con la que la animación designó a Karl Marx, quien tiene un rol activo y combativo contra las desigualdades sociales atribuidas a la Revolución Industrial del siglo XIX.

13 El rol del villano estereotipado del capítulo lo personificaría Mr. Arkwright. Enfrentado al héroe prototipo de las animaciones infantiles (Ivelic, 1982), el grueso dueño de la fábrica estaba vestido elegantemente con sombrero de copa y traje. De personalidad corrupta y malhumorado, estaba interesado únicamente por el dinero frente a James, el operario de la fábrica. Este operario, por su parte, vestía uniforme, era de complexión delgada y mostraba unas evidentes ojeras, claros signos de cansancio, agotamiento y mala alimentación. 
De esta manera, la diferenciación de los roles de los economistas que han encarnado el capitalismo y el marxismo se produjo de una manera totalmente abrupta. Después de que Zamba cuestionara la existencia del trabajo infantil, Adam Smith simplemente pidió perdón (en idioma inglés) ${ }^{14}$ por esa situación. Luego desapareció de la trama argumental del capítulo, dejando al protagonista de la animación perdido, aislado e indefenso. Esa situación se resolvió cuando Zamba fue rescatado de los engranajes ${ }^{15}$ de una fábrica por el propio Karl Marx (figura 3). Con esta conducta, cualquier televidente podría asociar la figura del economista prusiano con la del héroe clásico de las aventuras gráficas o los dibujos animados. Además, estaba en clara oposición al comportamiento negligente de Adam Smith.

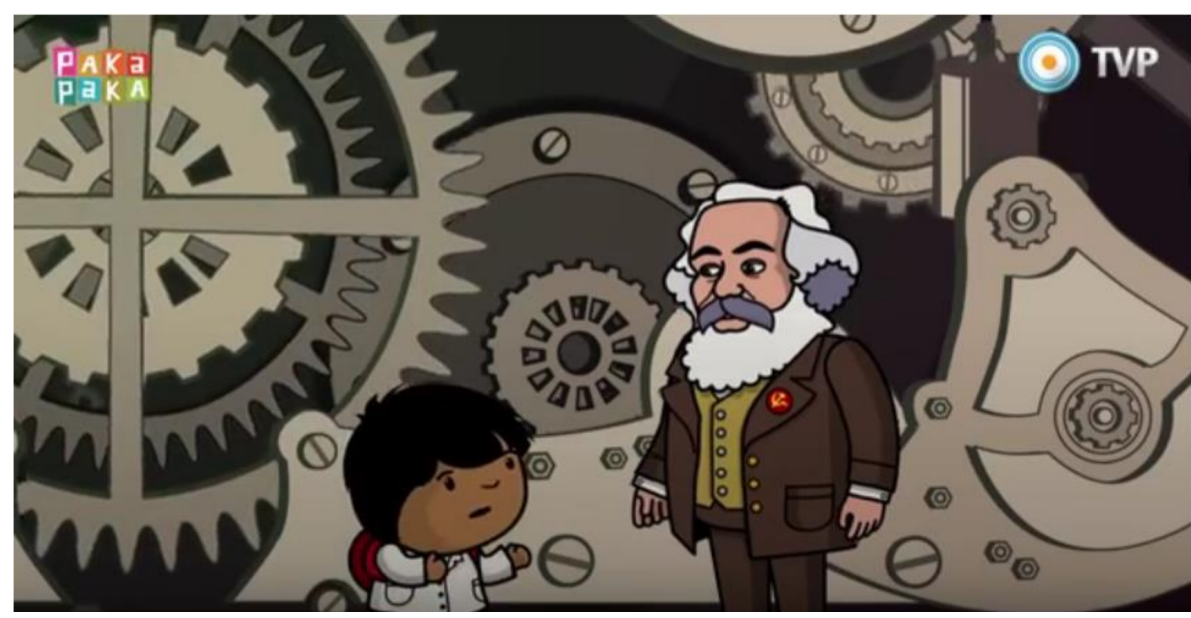

Figura 3. Karl Marx en la animación Zamba Fuente: Di Tirro et al. (2014).

El acento de la voz de los personajes fue otro factor relevante en la animación. El dibujo animado argentino también diferenció a los dos economistas por medio de características prosódicas. En la serie, el carácter extranjero de Adam Smith fue enfatizado hasta el absurdo, ya que está innegablemente asociado con un marcado y burdo acento inglés (que no escocés). Esta situación no ocurrió con el economista de Tréveris, el cual presentó un acento neutro y no el característico acento alemán de pastiche que se supondría que Marx debería tener. Esto podría considerarse como un intento de presentar a Karl Marx a los menores argentinos de una manera más cercana y familiar, en contraposición a la imagen estereotipada y ajena con la que los niños podrían identificar a Adam Smith.

14 El discurso de Adam Smith enfatizaba la idea de que, gracias a los avances tecnológicos, la gente tenía más tiempo libre para disfrutar del ocio, hecho que Zamba cuestionó rápidamente al contemplar la existencia de niños trabajadores en las ciudades.

15 Véase la enorme similitud de esa escena con la película Tiempos modernos (Chaplin, 1936). 
Además del tiempo, se consideraron el entorno y el rol que desempeñaron los dos economistas en la trama de la serie. Fue llamativo describir la valencia del lenguaje que usaron tanto Smith como Marx en toda la producción audiovisual, pues en este aspecto también se encontraron disimilitudes relevantes. El primero utilizó adjetivos positivos ${ }^{16}$ para ilustrar los avances de la industrialización y su legado histórico -incluso se llegó a identificar el personaje, de manera egocéntrica, con el propio dinero físico ${ }^{17}$ - pero obviaba, ignoraba o minimizaba sus consecuencias negativas más irrebatibles. En contraste, el lenguaje presente en el discurso de Karl Marx se caracterizaba por reflejar una valencia negativa ${ }^{18}$ de ese mismo entorno.

La disparidad entre los economistas que se percibió fácilmente en este episodio se resume en la siguiente síntesis:

- Características de la representación de Adam Smith: un agente pasivo de origen extranjero; representante del sistema económico capitalista y del establecimiento de la modernidad a cualquier precio, del ánimo de lucro y de la desigualdad social. Con la implementación negligente de este modelo, surgieron avances para una minoría privilegiada y problemas no solventados para el resto de la sociedad.

- Características de la representación de Karl Marx: un sujeto activo, más cercano al acervo nacional argentino; representante del sistema económico socialista que promovía la eliminación de las desigualdades sociales y la lucha contra la injusticia, la corrupción y la esclavitud. Con su implementación se solventarían los males surgidos por la aplicación del capitalismo.

\section{Discusión y conclusiones}

Al igual que el popular personaje animado de Condorito — creado en 1949 por el chileno René Ríos, el cual representó muy bien cómo pensaba y actuaba la América Latina mestiza del siglo XX por medio de sus rasgos de personalidad típicos y sus contradicciones ${ }^{19}$ (Páramo, 2009)—, Zamba era un niño originario de una provincia con un importante legado indígena y colonial. Para el Gobierno kirchnerista, Zamba representó la identificación de la Argentina diversa, en contraposición al tradicional

16 Los adjetivos pronunciados por Adam Smith fueron glorioso, flamante, inmortal, grandioso, fácil, barato, fantástico, eficiente o científico. Estos son algunos ejemplos que reflejan ingenuamente la visión capitalista de la Revolución Industrial en el capítulo analizado.

17 Como Zamba no entendía qué hacía un economista del siglo XVIII en un siglo posterior, Adam Smith le contestó altivo que él era inmortal, y le preguntó si no había visto su rostro en los billetes de veinte libras.

18 Los adjetivos pronunciados por Karl Marx fueron desbordado, complejo, (jornadas laborales) largas, (salarios) bajos, o cansado. Estos son otros ejemplos que determinarían la pretendida visión marxista de la Revolución Industrial.

19 Según Páramo (2009), Condorito representaba la crítica irreverente hacia los perpetuos estereotipos raciales y sexistas. 
etnocentrismo porteño de los medios de la nación ${ }^{20}$ (Álvarez-Gandolfi, 2013; Centanni, 2018). Esta caricatura también significó una reinvención de iconos nacionales que se contrapusieron a otras síntesis descriptivas de la otredad como el popular icono de Mundialito ${ }^{21}$, la mascota oficial del mundial de fútbol de Argentina en 1978 organizado por la dictadura militar argentina. Este personaje representaba el ideal gaucho blanco (Arrieta, 2014) que fue utilizado por el régimen para representar un ente tan abstracto como el ser nacional por medio de su estereotipo más notorio (Gómez, 2001).

Zamba y su lectura representó muy bien la división política de la sociedad argentina durante el mandato de la presidenta Cristina Fernández de Kirchner, en especial en la emisión de algunos capítulos que tratan sobre la historia más reciente del país ${ }^{22}$. A partir del año 2006, con la nueva Ley de Educación Nacional — promulgada en el Gobierno de Néstor Kirchner) - que decretó enseñar a las nuevas generaciones los episodios históricos y políticos anticonstitucionales y antidemocráticos (Pappier, 2016) de la vida republicana argentina, se impulsaron numerosas políticas audiovisuales para cumplir con esta legislación. Para el oficialismo de esa época y sus seguidores, El asombroso mundo de Zamba era una serie animada que brindaba un aporte educativo autóctono. En este sentido, sus promotores consideraban que su mayor mérito era "vincular a los niños con el conocimiento, la historia, la cultura y la ética [interpelándolos] como ciudadanos y no como meros consumidores" (Pauloni et al., 2015, pp. 152-153). Por otra parte, los detractores de esta animación consideraban que era un producto nacionalista anacrónico ${ }^{23}$ que simplificaba y distorsionaba la historia para acomodarla al discurso gubernamental. Además, consideraban que esta serie descalificaba a la escuela y ridiculizaba a los próceres de la patria argentina (San Martín, 2014). Por ello, la relación entre este dibujo y el modelo educativo defendido por el kirchnerismo era innegable. En este sentido, afirma Aragón (2016):

Estas propuestas necesariamente fueron pensadas en concordancia con algunas transformaciones que se habían dado en la última década, durante los gobiernos de Néstor Carlos Kirchner y Cristina Fernández, cuando diversas cuestiones relacionadas a la historia y a las formas de percibir y analizar el mundo habían cambiado sustancialmente. Esto se debió, en parte, a un giro

20 Obsérvese el contraste entre el tradicional rol de las mujeres en los medios de información de países de América Latina y el particular perfil (Vázquez-Miraz, 2019) de la única protagonista de la serie: Niña, una menor afrodescendiente. Este perfil contrasta, nuevamente, con el ideal argentino de raza blanca. Ahora bien, para Ensenada (2018) la serie presentaba continuos estereotipos de género en el que lo femenino se consideraba negativo o un motivo de burla.

${ }^{21}$ Mundialito era un pequeño hombre, sin tiempo ni edad, vestido con el uniforme de la selección argentina (Gómez, 2001) que la sociedad argentina vio como un niño y fue bautizado Gauchito.

22 Véase, por ejemplo, el capítulo "La asombrosa excursión de Zamba en la Casa Rosada" (Fenoll, 2019).

23 Se recomienda ver el capítulo "La asombrosa excursión de Zamba en las Islas Malvinas" y leer los análisis de este material realizados por González, Pauloni y Codoni (2016) y Tobeña (2019). Desde nuestro punto de vista, este producto está más cerca de catalogarlo como propaganda nacionalista que como material educativo. 
de paradigma que había puesto en el centro de la escena a los derechos humanos y a la revisión del pasado como elementos fundamentales para entender tanto el presente como el futuro. Ineludiblemente, la complejidad de este proyecto político se vio reflejada de una forma particular en el sistema educativo. (p. 36)

Si bien el sesgo ideológico que impregnaba este producto infantil fue motivo de críticas (Struminger, 2012), otros autores, como González et al. (2016), comprendieron esta influencia política como un elemento social transformador que trascendía el ámbito partidario. En este sentido, cuestionaron las quejas que hicieron a la animación, pues para estos autores la asociación de este dibujo con los postulados de ciertos partidos políticos sería un argumento demasiado simplista. Esta crítica también se ha asumido en parte en este manuscrito, en tanto se reconoce que solo se ha analizado un único capítulo de la serie (y no su totalidad). Sin embargo, en este capítulo se evidencia un reduccionismo teórico exhaustivo entre los campos político-económicos del marxismo y el capitalismo que no recoge la diversidad de estos dos elementos tan complejos.

Aunque se asumen las anteriores limitaciones, el análisis sobre este programa educativo infantil conlleva a inferir que los contenidos de "La asombrosa excursión de Zamba a la Revolución Industrial" —y otras apariciones del personaje infantil en episodios significativos de la historia moderna y de la Argentina- expusieron una parcialidad ideológica con propósitos de aceptación política. Con este tipo de representaciones, el oficialismo kirchnerista desarrolló una relación con sus gobernados durante los años en que estuvo en el poder. En esa proyección ideológica, el Gobierno se acercó a posiciones que reivindicaban versiones de la historia que coincidían con los postulados de izquierda. Estos postulados sirvieron de plataforma para desarrollar un estilo de autoridad que privilegió un discurso ideológico de tinte popular que se acercaba a las agremiaciones sociales de estudiantes, sindicatos o colectivos sociales.

Esta cosmovisión también recaló en públicos sensibles a la instrucción ideológica: los niños y jóvenes que asistían a la educación primaria y secundaria. Esto se debe a que los elementos enunciativos fueron adaptados para la producción y distribución de discursos eficaces a fin de generar una impronta histórica que resaltara iconos y contenidos modelados en sintonía con los postulados del kirchnerismo. Este proceso conllevó a la redefinición del sentido y la comprensión de la historia nacional para públicos que conectaran con este tipo de propuestas audiovisuales. En este contexto, el público infantil es uno de los más sensibles y participativos en los procesos de formación y apreciación de los contenidos históricos.

A su vez, este discurso ofreció una interpretación de la historia argentina en perspectiva kirchnerista. Esta versión funcionó como la exposición de contenidos históricos mediados por las necesidades de reivindicar o justificar lógicas de poder. Estas 
reivindicaciones fueron representadas con personajes animados que se valoraron de forma positiva o negativa y que funcionaron como arquetipos en los que se sintetizaron modos de ser antagónicos en la vida social. El capítulo que concentró el análisis de este manuscrito dio cuenta de una aproximación a la argumentación del marxismo clásico y una identificación con este, aunque debemos ser conscientes de la heterogeneidad de este concepto político (Laclau, 2006). Desde este alineamiento, la serie de televisión hizo una crítica al capitalismo al representar la Revolución Industrial como un período oscuro y negativo que la lucha obrera y popular (y de manera implícita el kirchnerismo) rechazaron y cuestionaron.

De esta manera, el programa infantil y sus contenidos han reproducido relatos históricos que presentan a los diferentes públicos una lucha dicotómica entre "buenos" y "malos". En este contexto, los intereses, puntos de vista y reivindicaciones del Gobierno kirchnerista crearon un espectro de elementos positivos en sintonía con los presupuestos gobiernistas de la época, los cuales se enfrentaron con motivos negativos, cuestionados y reprobados que contrariaban el discurso oficialista ${ }^{24}$. El clásico modelo dicotómico de la narrativa animada, donde un héroe protagonista se enfrenta y supera a un otro antagonista, es reproducido en los programas infantiles de la parrilla de televisión estatal (Gomes, 2016). Esta visión polarizada de la historia argentina, la cual fue rechazada por diferentes medios de comunicación críticos con el Gobierno de Cristina Fernández de Kirchner, como La Nación (Struminger, 2012) y Clarín (Varela, 2015), fue defendida por los creadores de la obra audiovisual, quienes afirmaron que en la animación había una nueva mirada histórica (Gastaldi, 2015).

Pese a todo, la serie también identificó elementos optimistas y progresistas de la industrialización. En este sentido, reconoció, a través del diálogo de Adam Smith, que esta dejó elementos positivos en la sociedad moderna, como el avance científico y tecnológico, entre otros. Sin embargo, la versión de la Revolución Industrial estuvo mediada por el personaje Smith, un individuo extranjero, egocéntrico y negligente; este personaje contrasta, de manera notable, con el solidario, bienintencionado y altruista Karl Marx. En este punto, la obra mostró abiertamente una visión sesgada que riñe con los criterios de ecuanimidad que presuntamente deberían tener los contenidos educativos y su difusión en públicos en formación.

Como afirmó Canales (1994) "el debate sobre las condiciones de vida de los trabajadores ingleses durante la primera mitad del siglo XIX es un debate ideológico, en el que se valora la eficacia del sistema capitalista [...] para asegurar la felicidad del

24 Esta situación no fue única de Argentina. Como antecedentes similares en países occidentales, se puede destacar al programa de televisión española de los años ochenta La bola de cristal, en el que el argumento giraba alrededor de una crítica mordaz del sistema capitalista (Rico, 2003). Paradójicamente, la antagonista de este programa (la bruja Avería) se convirtió en el personaje más popular y aclamado por el público, y su frase sigue siendo recordada hoy después de tantos años: "Viva el mal, viva el capital". 
mayor número de personas en la Inglaterra de la época" (p. 171). Esta es una discusión teórica de imposible resolución porque, además de las evidentes implicaciones ideológicas, también está presente la imprecisión de las pruebas aportadas por las dos perspectivas económicas y, de forma particular, la poca validez de los datos y registros cuantitativos (Canales, 1994). El hecho de que la animación empleara estereotipos clásicos, como el marcado acento extranjero de personajes con el fin de identificar fácilmente el antagonista del episodio — como se hizo con los actos de Mr. Arkwright—y de inducir un cambio de ideología en los receptores — como era la pretensión de Adam Smith con Zamba-, pudo producir una conducta evasiva por parte de la audiencia por el hecho de asociar estos elementos como simples agentes externos que no fueron interiorizados (Cooper y Jahoda, 1947).

En definitiva, este documento no pretendió asumir la hipótesis de que ciertos hechos históricos negativos deberían ser obviados en los espacios educativos destinados a un público infantil ${ }^{25}$. Al contrario, nunca se puso en duda la importancia de interesarse por presentar los aspectos negativos de la Revolución Industrial y el inicio del sindicalismo a los más jóvenes de una manera llamativa y divertida. El objetivo de este estudio, además de analizar un producto audiovisual de carácter formativo, es fomentar un espacio de debate acerca de la falta de neutralidad y la utilización política de los medios de comunicación públicos a través de un estudio de caso.

Se ha asumido que este artículo expuso una mayor evidencia de que, ya avanzado el siglo actual, los intereses de los partidos políticos argentinos siguen prevaleciendo frente a los pedagógicos en el ámbito de los medios de comunicación de carácter público, incluso en los contenidos dirigidos a la educación infantil, sin distinción de ideología política (ya avanzado el Gobierno de Mauricio Macri (2015-2019) y únicamente por decisiones políticas, esta popular caricatura perdió toda importancia (PedridoNanzur, 2018; Belinche-Montequín, 2019)). Esta situación hace recordar lo vivido en esta nación durante el primer Gobierno del general Perón en el que "la introducción y enseñanza obligatoria en los distintos niveles del sistema (sobre todo a partir de 1949) de contenidos de corte político-partidario" era una constante (Perrupato, 2013, p. 154) o el período de la última dictadura militar donde la continua propaganda antimarxista llegaba hasta los menores de edad (Pineau, Mariño, Arata y Mercado, 2006).

\section{Referencias}

Ahmad, S.R., Rodzi, M., Shapiei, N.S., Mohd-Yusop, M. y Ismail, S. (2019). A review of feature selection and sentiment analysis technique in issues of propaganda. International Journal of Advanced Computer Science and Applications, 10(11), 240-245. http://dx.doi.org/10.14569/ IJACSA.2019.0101132

25 Véase por ejemplo el brillante capítulo "La asombrosa clase de Zamba sobre la memoria" en el que se ha tratado varios casos de genocidios de la historia mundial (Sabich, 2017). 
Álvarez-Gandolfi, F. (2013). ¿La asombrosa excursión de Zamba en las escuelas? Cuadernos de H Ideas, 7(7).

Aragón, M. (2016). El nuevo/viejo rol de la educación. Letras, 4, 35-39.

Arrieta, D. (2014). La identidad nacional de los estados brasileño y argentino como construcción literaria a través de las figuras del bandeirante y del gaucho. Revista História e Cultura, 3(1), 105-1 19. http://dx.doi.org/10.18223/hiscult.v3i1.1188

Aschieri, N. E. (2017). Los robots en el sesquicentenario de Das Kapital. Céfiro. Revista de Economía y Gestión, 4(3), 89-100.

Bardin, L. (1996). Análisis de contenido. Akal Ediciones.

Bartra, A. (2014). El hombre de hierro. Limites sociales y naturales del capital en la perspectiva de la Gran Crisis. Universidad Autónoma de México.

Belinche-Montequín, M. (2019). Una que sepamos todos. Imágenes sonoras en La asombrosa excursión de Zamba. Arte e Investigación, 15, 1 -9. http://dx.doi.org/10.24215/24691488e025.

Bernardo, N. (2015). Pakapaka, una cartografía posible sobre la construcción de subjetividades y las tecnologías. Oficios terrestres, 33, 121-131.

Bohoslavsky, E. (2016). Cambios en la historiografía académica en Argentina (2001 2015). História da Historiografia, 9(20), 102 120. http://dx.doi.org/10.15848/hh.v0i20.967

Canales, E. (1994). Industrialización y condiciones de la vida en Inglaterra: Notas sobre una larga polémica. Investigaciones históricas. Época moderna y contemporánea, (14), 171 196.

Centanni, A. (2018). La escuela de Belgrano en Jujuy: entre la historia y la memoria. Cuadernos chilenos de historia de la educación, (9), 81-103

Chaplin, C. (productor y director). (1936). Tiempos modernos [cinta cinematográfica]. United Artists.

Cooper, E. y Jahoda, M. (1947). The Evasion of Propaganda: How Prejudiced People Respond to Anti-Prejudice Propaganda. Journal of Psychology, 23(1), 15-25. http://dx.doi.org/10.1080/002 23980.1947.9917316

Crivelli, S. (2015). Las aventuras de Zamba. Apuntes sobre la comunicación audiovisual en un canal infantil del Ministerio de Educación Argentino. Littera Aperta, 3, 75-89.

Di Tirro, C., Fanego, C. (productores) y Mignogna, S. (director). (2014). La asombrosa excursión de Zamba a la Revolución Industrial [serie de televisión]. El Perro en la Luna.

Escudero, A. (2002). Volviendo a un viejo debate: el nivel de vida de la clase obrera británica durante la Revolución Industrial. Revista de Historia Industrial, (21), 13-60.

Fedorov, A. (2015). The Application of Hermeneutical Analysis to Research on the Cold War in Soviet Animation Media Texts from the Second Half of the 1940s. Russian Education and Society, 57(10), 817-829. http://dx.doi.org/10.1080/10609393.2016.1148951

Fedorov, A. (2016). Soviet Cartoons Media Texts in Cold War Times: Hermeneutic Analysis. Russian Journal of Sociology, 3(1), 4-9. http://dx.doi.org/10.13187/rjs.2016.3.4 
Fenoll, V. (2019). La representación de la dictadura en el cine de animación argentino. Vivat Academia. Revista de Comunicación, (149), 45-66. http://dx.doi.org/10.15178/va.2019.149.45-66

Gambina, J. (2016). Marx: la crítica a la enseñanza universitaria de la Economía Política. Argumentum, 8(2), 153-166. http://dx.doi.org/10.18315/argumentum.v8i2.11845

Gastaldi, S. (2015). La construcción de la memoria en cuentos animados. Un análisis de "La asombrosa excursión de Zamba”. En M. F. Carcar, M. Rodríguez, P. Ponza y A. Álvarez (coords.). Actas del VIII Seminario Regional del Cono Sur de la Asociación Latinoamericana de Investigación en Comunicación (ALAIC) (pp. 58-67). Córdoba: Universidad Nacional de Córdoba.

Gastón-Wainer, A. (2018). Economía y política en la Argentina kirchnerista (2003-2015). Revista Mexicana de Sociología, 80(2), 323-351. http://revistamexicanadesociologia.unam.mx/index. $\mathrm{php} / \mathrm{rms} / \mathrm{article} / \mathrm{view} / 57720$

Gomes, G. (2016). Valoraciones y prejuicios sobre La asombrosa excursión de Zamba. Clío E Asociados. La historia enseñada, (23), 37-50.

Gómez, A. (1989). Ferrocarril, industria y mercado en la modernización de España. Espasa-Calpe.

Gómez, P. (2001). Imaginarios sociales y análisis semiótico. Una aproximación a la construcción narrativa de la realidad. Cuadernos de la Facultad de Humanidades y Ciencias Sociales, (17), 195-209.

González, L., Pauloni, S. y Codoni, M. (2016). De dónde viene y hacia dónde va la televisión educativa, cultural y pública en la Argentina. Oficios Terrestres, (34), 24-36.

González, L., Pauloni, S., Novomisky, S., Codoni, M. y Gómez, A. (2016). Perspectivas para pensar contenidos educativos infantiles. El concepto Edu-entretenimiento en la televisión Digital Argentina. Actas de Periodismo y Comunicación, 2(1). 1-17.

Honsa, T. (2012). Dr. Benson's cold war prescription: How a cartoon series presaged America's cold war lifestyle. Journal of Popular Film and Television, 40(4), 202-211. http://dx.doi.org/10.108 0/01956051.2011.653419.

Ivelic, R. (1982). Televisión infantil y dibujos animados. Aisthesis, (14), 55-64.

Jack, C. (2015). Fun and Facts about American Business: Economic Education and Business Propaganda in an Early Cold War Cartoon Series. Enterprise E Society, 16(3), 491-520. http:// dx.doi.org/10.1353/ens.2015.0036

Korstanje, M. (2016). De la Crisis Financiera en 2001 a la Filosofía de la grieta: la política argentina contemporánea. Reflexiones Marginales, (33).

Laclau, E. (2006). Ideology and post-Marxism. Journal of Political Ideologies, 11(2), 103-114.: https:// dx.doi.org/10.1080/13569310600687882.

Levav, M. (2005). Neuropsicología de la emoción. Revista Argentina de Neuropsicología, (5), 15-24.

Linare, C. y Cuesta, V. (2015). Incursionando en el asombroso mundo de Zamba. El Toldo de Astier, 6(10), 92-100.

Martín-Serrano, M. (1978). Métodos actuales de investigación social. Akal.

Mercader-Uguina, J. R. (2017). El impacto de la robótica y el futuro del trabajo. Revista de la Facultad de Derecho de México, 67(269), 149-174. http://dx.doi.org/10.22201/fder.24488933e.2017.269.62438 
Murolo, N. (2013). La asombrosa excursión de Zamba. Un viaje animado por la historia en la televisión pública argentina. Chasqui, Revista Latinoamericana de Comunicación, (122), 89-95.

Palermo, V. (2015). La alegría y la pasión. Relatos brasileños y argentinos en perspectiva comparada. Katz Editores.

Pappier, V. (2016). La transmisión del pasado reciente argentino a través de los manuales escolares. Una mirada desde Raymond Williams. Aletheia, Revista de la Maestría en Historia y Memoria de la FaHCE, 6(12), 1-17.

Páramo, C. (2009). No uno, sino muchos... motivos de Condorito. Maguaré, (23), 225-264.

Pauloni, S., Codoni, M., Noskwe, E. y Gómez, A. (2015). Procesos integradores en la Televisión Digital Pública. Anuario de investigaciones, 11(1), 141-154.

Pedrido-Nanzur, V. (2018). El Asombroso Mundo de Zamba: Análisis de géneros y sexualidades en una serie animada. En M. Campagnoli (coord.). V Jornadas CINIG de Estudios de Género y Feminismos (pp. 2-13). Nacional de La Plata.

Perrupato, S. (2013). Historiografía y educación peronista: un estado de la cuestión sobre historia de la educación durante el primer peronismo. Historia y Espacio, (40), 149-165.

Pineau, P., Mariño, M., Arata, N. y Mercado, B. (2006). El principio del fin. Políticas y memorias de la educación en la última dictadura militar (1976 1983). Colihue.

Rausky, M. (2009) Perspectivas sobre el trabajo infantil en la Argentina: Un análisis de las investigaciones desarrolladas en el campo de las Ciencias Sociales. Revista de estudios regionales y mercado de trabajo, (5), 177-200.

Retamozo, M. y Schuttenberg, M. (2016). La política, los partidos y las elecciones en Argentina 2015: chacia un cambio en el campo político? En Análisis Político, 29(86), 113-140. https://doi. org/10.15446/anpol.v29n86.58046

Riabov, O. (2018). "I am so glad i don't live in America in real life!" The image of the USA in gender discourse of Soviet animation (1946-1963). Woman in Russian Society, 2(1), 89-103. https://doi. org/10.21064/WinRS.2018.2.8

Rico, L. (2003). El libro de La bola de cristal. Plaza y Janés.

Rovner, H. y Monjeau, E. (2017). La mala educación: ¿Qué pasó con la escuela en la Argentina? Sudamericana.

Sabich, M. A. (2017). Infancias, genocidios, memorias. Representaciones discursivo-pedagógicas de procesos genocidas en el programa infantil La asombrosa excursión de Zamba (Pakapaka). Estudos em Comunicação, 25(1), 79-96. https://doi.org/10.20287/ec.n25.v1.a05

Salviolo, C. (2012). La experiencia de Pakapaka. En E. Duro (Ed.). Crecer Juntos para la Primera Infancia. Encuentro Regional de Políticas Integrales (pp. 120-124). Fondo de las Naciones Unidas para la Infancia (Unicef).

Sánchez, J. y Méndiz, H. (2013). La alfabetización mediática en la televisión infantil online: programas del Canal Pakapaka. Chasqui. Revista Latinoamericana de Comunicación, (124), 55-62.

San Martín, R. (2014 , 2 de febrero). Zamba: historia nacEpop para principiantes. La Nación. http:// www.lanacion.com.ar/1660556-zamba-historia-nacpop-para-principiantes 
Sosa, P. (2016). El surgimiento de la concepción política anticorporativa del Frente para la Victoria en Argentina. Estudios Políticos, (49), 55-72. http://dx.doi.org/10.17533/udea.espo.n49a03

Struminger, B. (2012, 3 de agosto). Un dibujito de Pakapaka cuenta la "historia oficial" en versión infantil. La Nación. http://www.lanacion.com.ar/1495635-zamba-de-paka-paka-relata-lahistoria-oficialen-version-infantil

Taylor, P. (2003). Munitions of the mind. A history of propaganda from the ancient world to the present day. Manchester University Press.

Tobeña, V. (2019). De la Clase de Historia a la Televisión: La Política Educativa Argentina en Torno a la Cuestión Malvinas a 30 años de la Guerra. Dados, 62(2). 1-30. https://dx.doi. org/10.1590/001152582019177

Varela, M. (2015, 15 de agosto). Las relecturas audiovisuales. Clarín. https://www.clarin.com/ cultura/san_martin-audiovisuales-zamba-pakapaka_0_BJbgjuNFPme.html

Vázquez-Miraz, P. (2019). El temprano retiro de las presentadoras de telediarios en Colombia y España: El repudio a la vejez femenina. Estudios sobre el Mensaje Periodístico, 25(2), 1171-1189. https://doi.org/10.5209/esmp.64832 